University of Warwick institutional repository: http://go.warwick.ac.uk/wrap

This paper is made available online in accordance with publisher policies. Please scroll down to view the document itself. Please refer to the repository record for this item and our policy information available from the repository home page for further information.

To see the final version of this paper please visit the publisher's website. Access to the published version may require a subscription.

Author(s): Parker, M. and Thomas, R.

Article Title: What is a Critical Journal?

Year of publication: 2011

Link to published article : http://dx.doi.org/10.1177/1350508411403535

Publisher statement: (C) Organization published by Sage. Parker, M. and Thomas, R. (2011).What is a Critical Journal? 18(4), pp. 419-427. 


\title{
What is a Critical Journal?
}

\author{
Martin Parker and Robyn Thomas
}

\section{What is Organization?}

Most competent editors should be able to make a clear statement about the scope, purposes and values of their journal ${ }^{1}$. The boundary that they then draw provides a ground for justifications of acceptance and rejection, as well as a description of some sort of community, or a group that broadly recognises itself as such. Sometimes, the community might be primarily articulated as oppositional, in the sense that it relies on not being something else. Organization, as a 'critical' journal with a strong statement about its distinctiveness, often seems to fall into this category. Implicitly or explicitly, 'they' are conservative whilst 'we' are radical. One term is defined by its other, and so a description of the conservatives is the antonym of the radicals. There is something comforting, even pious, about such a logic, suggesting, perhaps, that 'they' are stupid, narrow minded or deluded whilst 'we' are clear sighted and pure of heart. The logic is reversible of course, since the other side usually claims those virtues too. Such is the way that community and identity are often built, but it's an unstable set-up.

The instability comes, in part, from the empirical fact that the distributions of good and bad are rarely that well arranged, but also that any description of 'the other' is a tricky business. In ideal type terms, the others of the critical people are positivists, functionalists or modernists, but also sometimes patriarchs, imperialists, and hetero-normative defenders of the US pro-growth managerial hegemony. Of course 'we', who also mostly work in business schools, often use evidence and causation in our arguments, travel in aeroplanes, use iphones, and shop in supermarkets, might be accused of many of these sins too. We all live in glass houses, and should be careful where we throw stones. To complicate matters even further, much thinking and writing which seems to be on 'our' side happens in other places too. Journals like Organization Studies, Management Learning, Culture and Organization, ephemera, Human Relations and other journals in sociology, cultural studies, social history and so on often publish work which we would be proud to see in Organization. They don't often make so much of a fuss about it though, often preferring to claim that their distinctiveness is topic or quality, and perhaps that all good social science is critical, of which more later.

So if 'critical' work is being found in many places, perhaps Organization has achieved its aims, and should now retire gracefully with a final issue launched from the deck of an aircraft carrier and titled 'Mission Accomplished'. Sage Publications of Los Angeles, London, New Delhi, Singapore and Washington DC wouldn't be very pleased about that, but more about them later too. The problem is that any claim to draw a line in the sand between the critical and its other is a temporary matter, one that might be done here and now, but will rapidly become history as the wind shifts the grains. Terms that might have been important for Organization in 1994 - narrative, identity, ethics, discourse - have now firmly entered the mainstream and can be found pretty much everywhere, though perhaps with slightly changed meanings. Others - like postmodernism - have now become rather quaint. Very few people actually claimed to be postmodernists, even in 1994, and the term would now tend to be used as a general purpose dismissal which will set heads nodding amongst those who don't have much of an idea what they are agreeing about. It's a silly thing, postmodernism, that's all you need to know. Other terms, like Critical Management Studies, were whispers on the wind in 
1994, and the founding editors could have had no conception that it would grow into such a significant movement within a decade.

So if critique doesn't stay still, then how can a journal like Organization stay critical? In this short piece, stimulated by discussions at our editorial board meetings in 2010, the current editors reflect on this question. We begin by considering the historically located nature of the critical across the social sciences more broadly, before moving to a discussion of the tensions between institutionalisation and heterodox work. We conclude with some statements about how we intend to attempt to institutionalise critical ideas, and hence perhaps to try and deinstitutionalise Organization.

\section{Where and when is the Critical?}

In the last half century, virtually every discipline within the social sciences in the 'English speaking world' has developed a critical wing which claims that the centre of the discipline is conservative and that radical changes to the canon are required. The announcement of an avant garde is not a new phenomenon in itself, being an appellation commonly enough applied in art and literature, but it was given particular urgency as the currents of feminism and left politics swept through the academy from the mid 1960s onwards. Yet it's evident that 'critical' doesn't mean one thing. There are different histories and contexts to 'critical' work in different social sciences and humanities disciplines. The word doesn't mean the same in Literature as it does in Sociology, or Geography, or Cultural Studies, or the same in India that it does in the USA, or South Africa, or England. To make matters more complex, changes in the nature of academic careers, publishing patterns and outlets, the departmental structures of universities, and their national contexts have influenced the ways that the critical has emerged at different times and places. This means that questions of academic identity, whether disciplinary, national or political, shape and are shaped by specific histories (Bourdieu 1990, Becher and Trowler 2001) and cannot be assumed to be timeless. To say, now, in a journal like this, that you are 'critical' is a statement that necessarily assumes a great deal about context, but all too often this context is lacking, and some transcendental position is assumed. Castles in the air are summoned, and pronouncements made from on high, as if we already knew what mattered to the people who live in the shanty towns below.

One of the issues at stake here is a debate concerning the impact of academic work upon the politics of the places we inhabit. All academics have some sort of idea about how their research will insinuate itself into the world, whether via learned books read by their colleagues and students; providing evidence that leads to new forms of public policy and governance; or writing manifestos that attempt to inaugurate a different world. There are also often implicit political judgements embedded within these models. On the one hand we could imagine the social sciences and humanities as exploring problems which largely contribute to the maintenance or reform of existing cultural and social arrangements. On the other hand, 'critical' research and teaching would seek to radically change these arrangements through introducing, and then perhaps institutionalising, new forms of knowledge. There is no firm dividing line between these positions, but the politics of these disputes have made academic dissent into a terrain where principles and institutions have been regularly called into question. In other words, one of the most common beginnings for critical work is the recognition that knowledge has a politics, and hence that the institutions of knowledge production - universities, publishers, journals - have a politics too. At a personal level, this is now often called reflexivity, but this itself is a historically inflected form of the sociology of 
knowledge. All knowing comes from somewhere, and if you don't know where the somewhere is, your knowing will be more parochial than it need be.

In order to understand what it means to be 'critical' here, in this journal, it's worth thinking about what it means in other disciplines and times, and comparing them with our own. We could imagine 'mapping' the rise and fall of several different critical trajectories as a way of studying the formation of academic identities, and relating these to the forms of institutionalisation which are the precondition and outcome of such identities. If we take Critical Management Studies (CMS) as an example, since the mid 1990s this has become a term which has redrawn the map of one part of Business and Management. There is now a large bi-annual conference, websites and mailing lists; a few Business Schools which claim criticality as their distinctive orientation; textbooks and journals marketed as 'critical'; named Chairs in CMS; a special interest group of the US Academy of Management, and even an Oxford University Press handbook (Alvesson et al 2009, Parker 2010). This is an interesting example of the creation of disciplinary knowledge, and one that the participants themselves often reflect on in discussions about the costs and benefits of the 'mainstreaming' of CMS, often enough in the pages of this journal (Grey and Willmott 2002, Walsh and Weber 2002, Cooke et al 2008) $)^{2}$. So whilst it has been fairly routine for social science academics in many disciplinary contexts to claim to be 'critical', the nature of this claim is rarely scrutinised in a comparative manner. If it is primarily a claim about identity, then what sorts of 'markers' are being articulated and how do they relate to changes in the practices of academics and changes in the institutions in which they work, or that fund the places they work? If it is a claim about the potential or practicality of 'impact', then what sort of general implications might this have for research, teaching and public policy?

Of course many academics would argue that all good work in the social sciences is critical, in the sense of being sceptical of common sense, and regarding all arguments as provisional and dependent on evidence. This is fair enough, but here we are specifically interested in disciplinary developments in the English speaking academic world which self-consciously claim dissent as their distinctiveness. This is work which announces a radical rupture from the history of its discipline, and which (for a variety of reasons) claims that what passes for the canon is conservative. We can take, for example, the foundation of self-consciously 'critical' journals as an example of the general issue we are discussing here. Organisation was founded in 1994, but this is comparatively late. Antipode, Critical Sociology and the Review of Radical Political Economics were founded in 1969, Radical Philosophy in 1972, Critique in 1973, Critical Enquiry in 1974, Critical Social Policy in 1981, Critical Studies in Media Communication in 1984, and Critical Criminology in 1989. There is then a gap, into which Organization falls, followed by an increasing number of journals established in the last ten years - Critical Social Work and Critical Psychology in 2000, Journal for Critical Education Policy Studies in 2003, Critical Perspectives on International Business in 2005, Critical Literacy and Critical Policy Studies in 2007, International Journal of Critical Statistics, Critical Studies on Terrorism, The International Journal of Critical Pedagogy, and International Journal of Critical Indigenous Studies in 2008, International Journal of Critical Accounting and The Journal of Critical Globalization Studies in 2009. The rise in the number of journals in the last decade almost certainly reflects the interests of publishers as well as academics, but it seems to us significant in the sense that their editors, and publishers, must have assumed that there was a 'market' for ideas branded as 'critical'.

However, not all of these developments can be clearly identified by the use of the word 'critical' because a variety of synonyms have played similar roles - heterodox, radical, 
humanist, Marxist, feminist, green and so on. What counts as critical depends on what counts as dominant, and on the nature of the constituency which is claiming exclusion. In the broadest of terms, the 1960s and 1970s versions of criticality were either Marxist, or feminist, or both. So, for example, any academic work in any discipline which identified itself as taking a feminist perspective would necessarily rely on the assumption that its discipline suffered from the dominance of patriarchal ideas and structures. For the editors of a journal such as Signs (launched in 1975) anyone studying sex, gender and sexuality would necessarily be critical of the established academic order. From the 1980s onwards, newer versions of what it means to be critical appear to have tended more to post-structural positions. Post-colonialism, for example, might instantiate disciplinary knowledge as racist or exclusionary based on textual evidence rather than empirical studies of imperialism. Queer theory would question epistemology and representation, but rarely engage in spelling out programmes of institutional engagement or social change. Debates between those claiming to be critical then often became very acrimonious, with 'traditional' forms of empiricism or realism colliding with the post-foundational perspectives broadly influenced by the 'linguistic turn'. Within Management, for example, the very term CMS was taken by labour process Marxists and materialist feminists to mean a Foucauldian or Frankfurt School project, and hence came under heavy criticism for its supposed lack of engagement with the materialist politics of the workplace (Thompson 2004, for example).

A further complexity is that some disciplines, notably Cultural Studies, claimed criticality from their inception. The elements of Social History, Sociology and Literature that were employed to create this new area in England in the early 1970s were originally defined as an attempt to understand the mechanisms of hegemony. As the discipline institutionalised and migrated to the USA and elsewhere, the early attempts at articulating a Gramscian politics were increasingly criticised from the view of post-colonial, feminist, queer and autonomist politics. In a North American journal like Social Text (founded in 1979) 'The Birmingham boys' associated with the Centre for Contemporary Cultural Studies began to look rather like the orthodoxy, and not the critical vanguard. Within the UK, a further issue was that Cultural and Media Studies had tended to become institutionalised within the polytechnic sector, and less so within the old universities. This sense of 'outsiderness' also appeared to contribute to the idea of a necessary politics for a discipline that lay outside the putative centres of intellectual power. For Sociology itself, though its constituent elements clearly predated any self-consciously critical turn, by the late 1960s a substantial constituency within the discipline identified itself as necessarily engaged in a struggle with power on either a macro or micro level. Some could even claim that the idea of a critical sociology (the title by then of a journal and many books) was oxymoronic. Andreski puts the idea well, in a dictionary of modern thought.

'critical sociology. An expression which in principle is a pleonasm, since all good SOCIOLOGY must be critical in the sense of insisting on probing and being ready to challenge current opinions. It is only because the main current of sociology has become apologetic that the justification for 'critical sociology' has arisen.' (in Bullock and Stallybrass 1977: 146)

In the UK, other disciplines with disciplinary links to Sociology, such as Criminology and Education, developed thriving critical literatures at the same time, but by the 1990s many had effectively moved away from their explicitly critical stances and toward positions where they could speak directly to those providing funding for policy advice and evaluation. For some, this has been understood as co-optation and compromise, as work on class and gender gave way to evaluations of the effectiveness of particular state policies. For others, it was the 
maturing of a project which was intended to have effects on the world, combined with the recognition that intellectual purity doesn't guarantee funding or impact.

In general then, we can conjecture that the trajectories of the critical within academic disciplines vary in many ways. What we don't know is whether there are patterns to the rise and fall of these ideas, and how they relate to different formulations of how research, teaching, policy advice or activism in the social sciences can or should 'impact' on society. As far as we can discover, no-one has systematically attempted to study these matters, either in terms of the comparison of critical projects, and consequent claims about what social science can achieve in terms of social change. Perhaps this is because of the necessary interdisciplinarity required, or perhaps because it is only now - half a century after 1960, and in a context where ideas of 'impact', 'evidence' and 'best value' are becoming dominant that the question can really be posed with the historical and comparative focus that it requires.

\section{Institutionalisation}

Even if the content of the critical cannot be determined a priori, one issue that might be considered further is the relation between critical work and various processes of institutionalization. It seems fairly obvious that a critical project must build some sort of structures or technologies if it is to endure and have impacts. However, it also seems evident that its very institutionalisation might produce structures which work to reproduce power and not to question it (Douglas 1987). In a work originally published in 1912, Ernst Troeltsch distinguished between churches and cults on the basis of their relative levels of institutionalisation, but also their tolerance of orthodoxy (1956). Using ideas from Weber concerning the routinisation of charisma, he suggested that the journey from cult, to sect, to denomination, to church is one that moves from informal to formal organization, from marginality to centrality, and from dissent to adjustment. Cults and sects that don't institutionalise don't survive, but if they do survive, members' intense commitments to personal and social change also become more moderate. It might be that the payoff for influence is accommodation, the co-optation and mellowing of the radical ideas that drove the social movement in the first place.

Perhaps Organization has moved from cult to denomination, and has become part of the institutional apparatus of a generation of academics. It is nearing its $20^{\text {th }}$ birthday, is abstracted and indexed in 33 different specialist databases, and has an impact factor which places it comfortably in the top half of the rankings for Management journals. It is published and owned by Sage, one of the largest journal publishers in the world, and has an editorial team which represents most of the key universities in the global north and has given at least one set of authors the impression that that it is a club of insiders (Jones et al 2006). In organizational terms, there is very little to distinguish it from most other elite academic journals. It is not a collective, it doesn't publish itself, its board members and authors are all academics and most of them are from Business Schools. It also employs a typical three tier reviewing process, in which reviewers, Associate Editors and an Editor in Chief need to broadly agree before something gets published. It's difficult to imagine a better way to ensure that difference is excluded, and the same gets reproduced, whether the participants in this process like it or not. It might well be that the subtitle 'the critical journal of organization, theory and society' is no more than middle aged hubris. If it looks like a duck, quacks like a duck and smells like a duck, then it's probably a duck, even it likes to claim that it is a velociraptor. 
Of course, at the risk of sounding like organization theorists, all institutions are sitting ducks for their environment. As soon as the journal began to publish, it began to find its way onto academic CVs which were always going to be submitted to promotions panels. It became one element in the profitability of Sage Publications. It became a reputational asset for departments and universities with respect to internal politics, research assessment exercises and global rankings lists. It became a source of comparative data for Thompson Scientific, who publish the journal citation reports based on a two year window that was invented for the natural sciences. It became a marketing tool for the UK Association of Business Schools, whose journal ranking list has brought much publicity to a previously rather moribund organization $^{3}$. And each of these actors reinforces each other, with editors trying to up their citation rates, academics being encouraged to publish in 'top ranked' journals if they want tenure or promotion, publishers using the impact factors of journals to market them, and so on. Almost imperceptibly, since 1994, Organization has become part of a complex network with rather functional outcomes for pretty much everyone concerned.

Other journals have responded to these isomorphic pressures in some remarkably intricate ways. Using the impact factors which have been aggressively marketed by Thompson Scientific since 1992 as the key driver, editors have adopted policies which artificially inflate citations. At the mellow end, this is no more than the injunction that if you want to be involved in a journal's 'conversation' you need to be aware of it, so referencing the journal you are publishing in may simply be a sign of engagement. However, there is much evidence that high impact factors are being produced by editors insisting on journal citations as a condition of the review, perhaps even suggesting papers that could be cited. Or, editors publish short editorials with references to the journal in every issue, or introductions to subsections of the journal. Review essays are also very good for generating citations, and there is now a common practice of publishing work that looks like it might be cited in early issues of the volume, in order that it has plenty of time to have 'impact' by the time Thompson do the census. Of course this is widely understood by the academics who publish in these journals, so there is probably an element of anticipated conformity to these citation practices too. In 2009, Organization's impact factor was just over 1.3, meaning that each article we published was cited an average of 1.3 times during 2007 and 2008. This was based on a total of 1092 citations during those years. By contrast the Academy of Management Review had an impact factor of 7.867, based on 14649 citations. That's just short of one citation an hour, for two years solid. Impressive huh?

The higher the impact factor, the better the journal is supposed to be, but better at what? Citations clearly mean something, but it is not clear what they mean. They could be an indicator of the power which certain journals have to define a field, and the consequent lack of pluralism or heterodoxy. It could mean that people read and cite only a very few journals, and that broader reading is discouraged. High citations could indicate something about the consensus over core problems and methods that exists in the centre of a discipline (and hence which mistakes parochialism for inclusiveness), or the sheer size of a particular national university system (which mistakes sheer scale for universality), or the dominance of a particular language (Meriläinen et al 2008, Grey 2010). They could tell us about the widespread acceptance of certain political assumptions, perhaps concerning the ways to imagine economies, organization and governance. They could even tell us about the way that books, and chapters in books, are being treated as inappropriate forms of output in some disciplines even while they are the gold standard in others. Or, they could tell us that authors need publications so badly, that they will follow the implicit rules on citation in order to get jobs, pay hikes, permanent positions, and promotions. They could also tell us something 
about the remarkable effectiveness of interlocking forms of institutionalisation to agree on what matters - making the simple matter of a reference in someone else's writing into a signal that produces all sorts of consequences. High citations could also suggest that the work was good and getting read, but that is only one possibility amongst many.

The point is that Organization, probably like the rest of the critical journals we listed above, is inevitably shaped by its context. The disciplinary and cultural background of the editors, the people they know who are usually like them, the common assumptions about what journals are for and who reads them, and the economics of the institutions which employ them. All these pressures tend to produce soft personal conformity, and institutional isomorphism. The leading edge ends up following, and the cutting edge only sharp enough for birthday cakes and collective congratulations. So can this journal stay different?

\section{Unique Selling Proposition}

As we asserted at the start, most competent editors should be able to make a clear statement about the scope, purposes and values of their journal, but we have also insisted that any such statement is out of date before it is written. So what might we say that would allow this journal to be different, but without fixing it as 'postmodernist', or the house organ of the CMS Central Committee, or whatever? At least two things are clear. Organization, if it is to continue as a journal, needs to carry on getting good papers, and neither can it afford to ignore the variety of organized networks it is embedded in. We might not like them very much, but we can't imagine that we are elevated above them either. Nonetheless, we can make some pretty clear statements of editorial policy. For example, we can afford to be explicit about our refusal to engage in the crude gerrymandering of Thompson Scientific's citation metrics in order to push us up league tables. It might make us more attractive to publish in if we did, particularly to those academics who work in national contexts or business schools that are strongly driven by such measures. This is a strategy that will result in us trying to treat the impact factor as of interest to librarians, and to those studying the production and consumption of knowledge, as some of the other contributions to this issue do. If you want to publish with us, write about Thompson Scientific by all means, as well as academic careers, university rankings and the forms of global capitalism which have produced gigantic publishing companies like Sage, and Thompson Scientific.

We want papers which understand that any form of institutionalised knowledge has a politics, and that means that publishing in a journal is not merely a line on a $\mathrm{CV}$, but an implicit claim about what problems matter (Dunne et al 2008). So the problems that matter for this journal are not those which are already being discussed elsewhere and dissected with a thousand cuts, but the awkward ones that don't really fit in other places. They should be questions that provoke unease, and the sort of reflection that doesn't sit easily within the core of disciplines and institutions. As the founding editorial statement argued, this is a call for 'neodisciplinarity' in the sense of encouraging the awkward and beautiful juxtapositions that can happen when ideas from different places meet (Burrell et al 1994). We can't tell you what these concepts are, because that is already to circumscribe what we want. We don't have a list of keywords, any more than it would have made sense for the founding editors to claim that they were interested in CMS in 1994. Neither do we want to be seen as the journal that only publishes CMS, or postmodernism, or narrativeidentitydiscourseethics or whatever the currently fashionable and vaguely left field term might be. Just as importantly, neither do we want to be seen as a journal which doesn't publish forms of Marxism or feminism on the grounds that they are old fashioned, or anarchism and environmentalism because they are 
outside the scope of the journal, or come from outside the Business School. We also want papers from outside the supposedly key locations of the global north. Over the past few years we have been expanding the number of Associate Editors in order to reflect the many places where we want the journal to matter. This means being particularly attentive to locations outside the USA and the UK in particular, and the Global North in general. We are nowhere near where we need to be on this yet, but hope that the changes that we have made so far will encourage any English speaking writers with an interest in our area to submit to us. It is easy enough to announce global ambitions and claim to be an 'international' journal, but hard to make that work in practice, but we will keep trying.

Finally, we don't want reading Organization to be a neutral experience, a sort of professional newsletter for careerists, or a dentist's waiting room magazine for distracted and disaffected business school academics ${ }^{4}$. The job of the editors of a journal like this should be to annoy and delight their readers (in equal measure, and perhaps at the same time) by publishing things that demand a response. If your work doesn't fit - because it is controversial, interdisciplinary, not written like a journal article - then perhaps you should submit to this journal. Yet in reviewing your 'submission', we will try to ensure that the demands of a broad agreement between referees, Associate Editors and Editors-in-Chief does not squeeze out work which is provocative, irritating or stylistically demanding. This might also mean annoying referees, if we end up ignoring their passionate doubts or objections to particular pieces. This is probably the most important issue, because it means trying to build an agreement about disagreement. Organization must not cultivate consensus, and should work against its own institutionalization - de-institutionalizing where it can in order to open the space for something new. We simply don't know what articles will have mattered in twenty years time, but we do know that if this journal doesn't try to be different, it will become the same. At the same time, in all that is good about being different, we want to be constantly vigilant over being the same, and staying with the impatient politics that motivated the founding of the journal in the first place.

\section{References}

Alvesson, M, Bridgman, T and Willmott, H (eds) (2009) The Oxford Handbook of Critical Management Studies. Oxford: Oxford University Press.

Becher, T and Trowler, P (2001) Academic Tribes and Territories ( $2^{\text {nd }}$ edition). Buckingham: SRHE/Open University Press.

Bourdieu. P (1990) Homo Academicus. Palo Alto, CA: Stanford University Press.

Bullock, A and Stallybrass, O (1977) The Fontana Dictionary of Modern Thought. London: Fontana.

Burrell, G, Calás, M, Reed, M, Smircich, L and Whitaker, A (1994) 'Why Organization? Why now?' Organization 1/1: 3-9.

Cooke, B, Perrow, C, Stookey, S, Adler, P, Willmott, H, Cunliffe, A and Voronov, M (2008) 'Speaking Out on the Future of Critical Management Studies' Organization 15/6: 912-945.

Douglas, M (1987) How Institutions Think. London: Routledge and Kegan Paul. 
Dunne, S, Harney, S and Parker, M (2008) 'The Responsibilities of Management Intellectuals: A Survey’ Organization 15/2: 271-282.

Editors (2003) ‘Why Neo-Disciplinary? Why Now?’ Organization 10/3: 403-420.

Grey, C (2010) ‘Organizing Studies’ Organization Studies 31/6: 677-694.

Grey, C and Willmott, H (2002) 'Contexts of CMS' Organization 9/3: 411-418.

Jones, O, Sharifi, S and Conway, S (2006) 'Accounting for Organization: Round up the Usual Suspects’ Accounting, Organizations and Society 17/2-3: 283-304.

Meriläinen, S, Tienari, J, Thomas, R and Davies, A (2008) 'Hegemonic Academic Practices: Experiences of Publishing from the Periphery' Organization 15/4: 584-597.

Parker, M (2010) 'The Sclerosis of Criticism: A Handbook of Critical Management Studies?' Critical Policy Studies 4/3: 297-302.

Thompson, P (2004) 'A critical reflection on Critical Management Studies'. In Fleetwood, S and Ackroyd, S (eds) Critical Realist applications in Organization and Management Studies. London: Routledge, 54-70.

Troeltsch, E (1912/1956) The Social Teachings of the Christian Churches. London: Allen and Unwin.

Walsh, J and Weber, K (2002) 'The Prospects for Critical Management Studies in the American Academy of Management' Organization 9/3: 402-410

\footnotetext{
${ }^{1}$ Grateful thanks to the members of the Organization board who commented on an earlier version of this essay.

${ }^{2}$ Citations to Organization which will improve our impact factor, and hence make this a better journal, or so the logic goes.

${ }^{3}$ Though such ranking metrics have brought concerted resistance in other areas, such as the collective statement from 56 history of science journal editors in 2009 demanding to be withdrawn from the European Reference Index for the Humanities. See www.ncbi.nlm.nih.gov/pmc//articles/PMC2629173/. The lack of a similar response in the Business School is interesting in itself. Would Sage allow Organization to withdraw from the Thompson ISI rankings?

${ }^{4}$ As Hugh Willmott suggested, more morphine than magazine.
} 